\title{
Acquisition and retention of monocular discriminations in rats as a function of relevant (reversal) or irrelevant opposite-eye training '
}

\author{
DANIEL M. LEVINSON ${ }^{2}$ AND CHARLES L. SHERIDAN \\ THE UNIVERSITY OF MISSOURI AND VA HOSPITAL, KANSAS CITY
}

Albino rats retained a monocular pattern discrimination even after interpolated mastery of a reversal or a black-white discrimination via the opposite eye. In the first experiment, a second-eye reversal problem was acquired more rapidly than the original pattern problem. The second experiment showed that monocular training on a black-white problem has a marked facilitatory effect on subsequent acquisition of a pattern discrimination with the opposite eye.

Following monocular acquisition of a horizontalvertical discrimination, albino rats show considerable savings when given the same monocular discrimination with the opposite eye open (Creel \& Sheridan, 1966). If reversal training is given with the opposite eye, originalproblem intrusions occur (Sheridan, 1965a), yet acquisition of the second-eye reversal takes place, if anything, faster than original learning. Upon returning to the originally trained eye, Ss select the original $S+$ as though reversal training had not intervened (Sheridan, 1965a). There seems, then, to be a peculiar compatibility of original and reversal discriminations when they are mediated by opposite eyes. It has been suggested (Sheridan, 1965a) that there might be an interocular facilitation of reversal discriminations related to the mirror-image reversal phenomenon in pigeons discovered by Mello (1965), and that the low levels of interocular transfer exhibited by rats in some situations (Sheridan, 1965b) might be due to some combination of an interocular reversal tendency and of veridical interocular transfer. The experiments reported here were done in order to evaluate this interocular interaction hypothesis.

\section{EXPERIMENT 1}

This experiment was concerned with the retention of monocular pattern discrimination after interpolation of contralateral reversal or irrelevant training.

Subjects

Fourteen male albino rats of the Sprague-Dawley strain were used as Ss.

\section{Apparafus}

The apparatus, a Thompson-Bryant (1955) box, utilized shock motivation and consisted of a startbox, runway, choice point with two entryways, and a goal box. Procedure

Ss were pretrained to run to the goalbox, and to knock over gray stimulus cards which blocked the goalbox entryways. One eye was then covered with an opaque con- tact occluder and Ss were trained to discriminate $1 / 2$ in. wide stripes tilting $45^{\circ}$ to the right vs $1 / 2$ in. wide stripes tilting $45^{\circ}$ to the left. The correct stimulus was chosen randomly for a given $S$, and the position of this stimulus was ordered across trials according to a Gellerman series. Training continued at a rate of 25 trials per day until a criterion of 18 correct responses in 20 consecutive trials had been met; then Ss were overtrained until they had met an additional criterion of 9 correct responses in 10 consecutive trials. If $S$ failed to meet criterion after 300 trials, no further training was given. After original-eye training, the occluder was shifted to the opposite eye and half of the Ss were given 200 trials of training on a black-white discrimination while the other half were given 200 trials of reversal training. After $S$ had completed the interpolated 200 trials, the occluder was shifted once again and 10 choicetrials were given. During these 10 trials, both pattern doors were unlocked and Swas given access to the goalbox without shock via either of them. Ss performing at a level of $90 \%$ original correct cue choices or better on these choice-trials were terminated. The remaining Ss were given further training on the original problem with the original eye open until a $9 / 10$ criterion had been met. Results

Retention on the original-eye test trials following second-eye learning was excellent whether black-white or reversal training had been interpolated. For the 10 test trials, the black-white group made a median of $100 \%$ correct (original correct cue) choices and the reversal group made a median of $85 \%$ correct choices. It was clear from inspection of individual data that there was no significant difference between the two groups. Reversal learning took place more rapidly than original learning. Since reversal learning was terminated at 200 trials regardless of performance levels, original and reversal trials to a $9 / 10$ criterion were compared. This criterion had the advantage of being a commonly used one which all Ss met on the reversal task. Median trials to criterion on the original pattern problem and on the reversal task were 182.5 and 104.5 , respectively. A Mann-Whitney $U$ test showed that this difference is significant $\left(\mathrm{U}=14, \mathrm{~N}_{1}=6, \mathrm{~N}_{2}=14, \mathrm{p}<.05\right.$, two-tailed). Discussion

These findings do not support the conjecture that, in rats, retention of a monocular discrimination during reversal learning via the opposite eye is aided by a mech- 
Table 1

Trials to criterion on the pattem task following black-white, reverse, or no prior discrimination training

\begin{tabular}{|c|c|c|c|c|}
\hline \multirow{3}{*}{$\begin{array}{l}\text { Pattern After } \\
\text { Black-White } \\
\text { S }\end{array}$} & \multicolumn{2}{|c|}{ Pattern After } & \multicolumn{2}{|c|}{ Pattern As } \\
\hline & $\mathrm{Re}$ & Tosk & $\ln \mathrm{i}$ & Tosk \\
\hline & $\$$ & & S & \\
\hline 29 & 16 & 104 & 16 & 55 \\
\hline 21 & 19 & 96 & 19 & 84 \\
\hline 43 & 22 & 35 & 22 & 80 \\
\hline 80 & 25 & 180 & 25 & 90 \\
\hline 30 & 28 & 97 & 28 & 123 \\
\hline Median $=29.5$ & & $=97.0$ & Med & $=84.0$ \\
\hline
\end{tabular}

anism which reverses cue valences during across-the -midline transfer.

Second-eye reversal learning was no more conducive to retention of the original discrimination than was second-eye learning of an irrelevant task. Since retention was excellent in both cases, it is possible that longer periods of interpolated second-eye learning would still reveal facilitation by the reversal task. However, the slightly lower median percentage correct on retention tests which followed reversal training does not encourage this interpretation.

\section{EXPERIMENT 2}

This experiment was concerned with the acquisition of a monocular pattern discrimination following learning of an irrelevant or reverse discrimination with the opposite eye.

If there is no interocular reversal effect, why does second-eye reversal learning tend to occur so rapidly? One possibility is that part of the discrimination learning task lies in the acquisition of something other than tendencies to approach and avoid the E-defined stimuli. For example, if a large part of original acquisition consists in reduction of position errors (Harlow, 1959), in bringing behavior under the control of the relevant stimulus dimension (Lawrence, 1949; Sutherland, 1963), or in some other type of learning which is general to a variety of specific tasks, original learning would assist in some aspects of reversal acquisition.

The second experiment helped to evaluate the notion that there is a substantial component of the discrimination task which is general to more than one kind of discrimination.

\section{Subjects}

Eleven male albino rats of the Sprague-Dawley strain were used as Ss.

\section{Apparafus and Procedure}

The apparatus and general procedure were the same as those used in Experiment 1. Six Ss were given monocular training on a black-white discrimination prior to training via the opposite eye on the pattern discrimination task. Five Ss were trained on the pattern discrimination with one eye, then given 200 trials of reversal training with the second eye.
Results

Trials to a $9 / 10$ criterion on the pattern task following black-white, reverse, or no prior discrimination training are shown in Table 1. No interocular facilitation occurred in this experiment as a result of original-eye learning of the reverse discrimination, nor was there any noteworthy impairment as a result of such learning. Black-white training with the original eye facilitated pattern discrimination acquisition markedly (MannWhitney $\mathrm{U}=1.5, \mathrm{~N}_{1}=5, \mathrm{~N}_{2}=6, \mathrm{p}<.02$ ).

\section{Discussion}

The facilitated second-eye reversal learning observed in Experiment 1 was not replicated in Experiment 2, except perhaps in the sense that some process seemed to compensate for any interfering effects which might accrue from having learned a reverse discrimination on the original eye. The reasons for the failure to replicate are not clear, though there were other differences between the performances of Ss in the first and Ss in the second experiment. For example, acquisition was generally much more rapid in the second experiment. Many factors could have influenced these outcomes, and it is pointless to speculate about them without undertaking further experimental manipulations.

Despite the absence of an interocular reversal facilitation effect, black-white training had a marked facilitatory effect on subsequent pattern discrimination with the opposite eye. Apparently there are atleast two components underlying acquisition of the pattern discrimination task-a component specific to the E-defined relevant stimuli and a component general to more than one kind of discrimination. In the present experiment the general component would seem to be far more weighty than the specific one.

\section{References}

Creel, D. J., \& Sheridan, C. L. Monocular acquisition and interocular transfer in albino rats with unilateral striate ablations. Psychon. Sci., 1966, 6, 89-90.

Harlow, H. Learning set and error factor theory. In S. Koch (Ed.), Psychology: a study of a science. New York: McGraw-Hill, 1959.

Lawrence, D. H. Acquired distinctiveness of cues: I. Transfer between discriminations on the basis of familiarity with the stimulus. J. exp. Psychol., 1949, 39, 770-784.

Mello, N. K. Interhemispheric reversal of mirror-image oblique lines after monocular training in pigeons. Science, 1965, 148, 252-254.

Sheridan, C. L. Interocular interaction of conflicting discrimination habit in the albino rat: a preliminary report. Psychon. Sci., 1965a, 3, 303-304.

Sheridan, C. L. Interocular transfer of brightness and pattern discriminations in normal and corpus callosum-sectioned rats. $J$. comp. physiol. Psychol., 1965b, 59, 292-294.

Sutherland, N. S. Stimulus analyzing mechanism. In K. M. Sayre \& F. J. Crosson, The modelling of mind. Notre Dame: Notre Dame Press, 1963.

Thompson, R. M., \& Bryant, H. Memory as affected by activity of the relevant receptors. Psychol. Rep., 1955, 1. 393-490.

\section{Notes}

1. Supported in part by 8200 funds from the Neuropsychology Laboratories, Kansas City V.A. Hospital and in part by Grant MH1226802, U. S, Public Health Service to Charles L. Sheridan.

2. Now at the University of Southern California. 